\title{
Human osteopontin: Potential clinical applications in cancer (Review)
}

\author{
CHENGCHENG HAO ${ }^{1,2}$, YUXIN CUI ${ }^{3}$, SIONEN OWEN $^{3}$, WENBIN LI $^{4}$, SHAN CHENG $^{1,2}$ and WEN G. JIANG ${ }^{1-3}$ \\ ${ }^{1}$ Department of Biochemistry and Molecular Biology, and ${ }^{2}$ Beijing Key Laboratory of Cancer and Metastasis Research, \\ Capital Medical University, Beijing 100069, P.R. China; ${ }^{3}$ Cardiff China Medical Research Collaborative, \\ Cardiff University School of Medicine, Heath Park, Cardiff CF14 4XN, UK; ${ }^{2}$ Department of Oncology, \\ Beijing Shijitan Hospital, Capital Medical University, Beijing 100038, P.R. China
}

Received January 3, 2017; Accepted April 10, 2017

DOI: $10.3892 /$ ijmm.2017.2964

\begin{abstract}
Human osteopontin (OPN) is a glycosylated phosphoprotein which is expressed in a variety of tissues in the body. In recent years, accumulating evidence has indicated that the aberrant expression of OPN is closely associated with tumourigensis, progression and most prominently with metastasis in several tumour types. In this review, we present the current knowledge on the expression profiles of OPN and its main splice variants in human cancers, as well as the potential implications in patient outcome. We also discuss its putative clinical application as a cancer biomarker and as a therapeutic target.
\end{abstract}

\section{Contents}

1. Introduction

2. Expression of OPN in human cancer

3. Expression of OPN splice variants in human cancers

4. Polymorphism of OPN and OPN splice variants in cancers

5. Conclusion and future perspectives

\section{Introduction}

Osteopontin (OPN) is a bone associated, extracellular matrix glycosylated phosphoprotein which is produced by several cell types, including osteoblasts, osteoclasts, immune cells, endothelial cells, epithelial cells and extra-osseous cells (skin, kidney and lung) (1-3). Due to differences in post-translational modification (PTM) (phosphorylation, glycosylation, sulfation and proteolysis) from different cellular sources, OPN has a molecular weight ranging from 41 to $75 \mathrm{kDa}$, which may have a cell type-specific structure and function (4-7). OPN plays a major role in various normal physiological processes, including

Correspondence to: Professor Wen G. Jiang, Cardiff China Medical Research Collaborative, Cardiff University School of Medicine, Henry Wellcome Building, Heath Park Way, Cardiff CF14 4XN, UK E-mail: jiangw@cf.ac.uk

Key words: osteopontin, splice variants, cancer, disease progress bone remodelling, immune-regulation, inflammation and vascularisation $(8,9)$. In addition, OPN has also been shown to be involved in carcinogenesis with multi-functional activities (10-12).

OPN is involved in a series of biological functions through interactions with different integrins and CD44. Therefore, OPN is classified as a member of the 'small integrin-binding ligand N-linked glycoproteins' (SIBLINGs) together with other molecules, including bone sialoprotein (BSP), dentin matrix protein 1 (DMP1), dentin sialophosphoprotein (DSPP) and matrix extracellular phosphoglycoprotein (MEPE) (13). Two critical integrin binding sequences of OPN have been identified: arginine-glycine-aspartic acid (RGD) and serine-valine-valinetyrosine-glutamate-leucine-arginine (SVVYGLR). OPN interacts mainly with various $\alpha v$ (particularly $\alpha v \beta 1, \alpha v \beta 3, \alpha v \beta 5$ ) integrin receptors via the classical RGD sequence, and interacts with $\alpha 9 \beta 1, \alpha 4 \beta 1, \alpha 4 \beta 7$ via SVVYGLR (14-16). In addition, it also interacts with the CD44 splice variants, CD44v3, CD44v6 and CD44v7, via the C-terminal fragment calcium binding site (17-20). These properties of OPN induce the activation of signal transduction pathways, leading to cell proliferation, adhesion, invasion and migration, which have been demonstrated by both in vitro and in vivo models (21-23). The binding of OPN to integrins and CD44 initiates a downstream signalling cascade via the PI3K/AKT signalling pathway leading to NF- $\mathrm{BB}$ mediated cell proliferation and survival (24-26). In additon, through the Ras/Raf/MEK/ERK signalling pathway, an OPN-integrin complex and subsequent induction of AP-1-dependent gene expression, urokinase-type plasminogen activator (uPA) and matrix metalloproteinases (MMPs) confer a metastatic phenotype on some cancer cell types (27-29). Induced by vascular endothelial growth factor (VEGF), OPN and certain integrins are able to promote angiogenesis through enhanced endothelial cell migration, proliferation and the subsequent formation of capillaries, which are all essential requirements for the process of angiogenesis $(30,31)$.

\section{Expression of OPN in human cancer}

OPN has been shown to correlate with tumourigenesis, as well as with the progression and metastasis of different malignancies in both experimental and clinical studies (Table I). The upregulation 


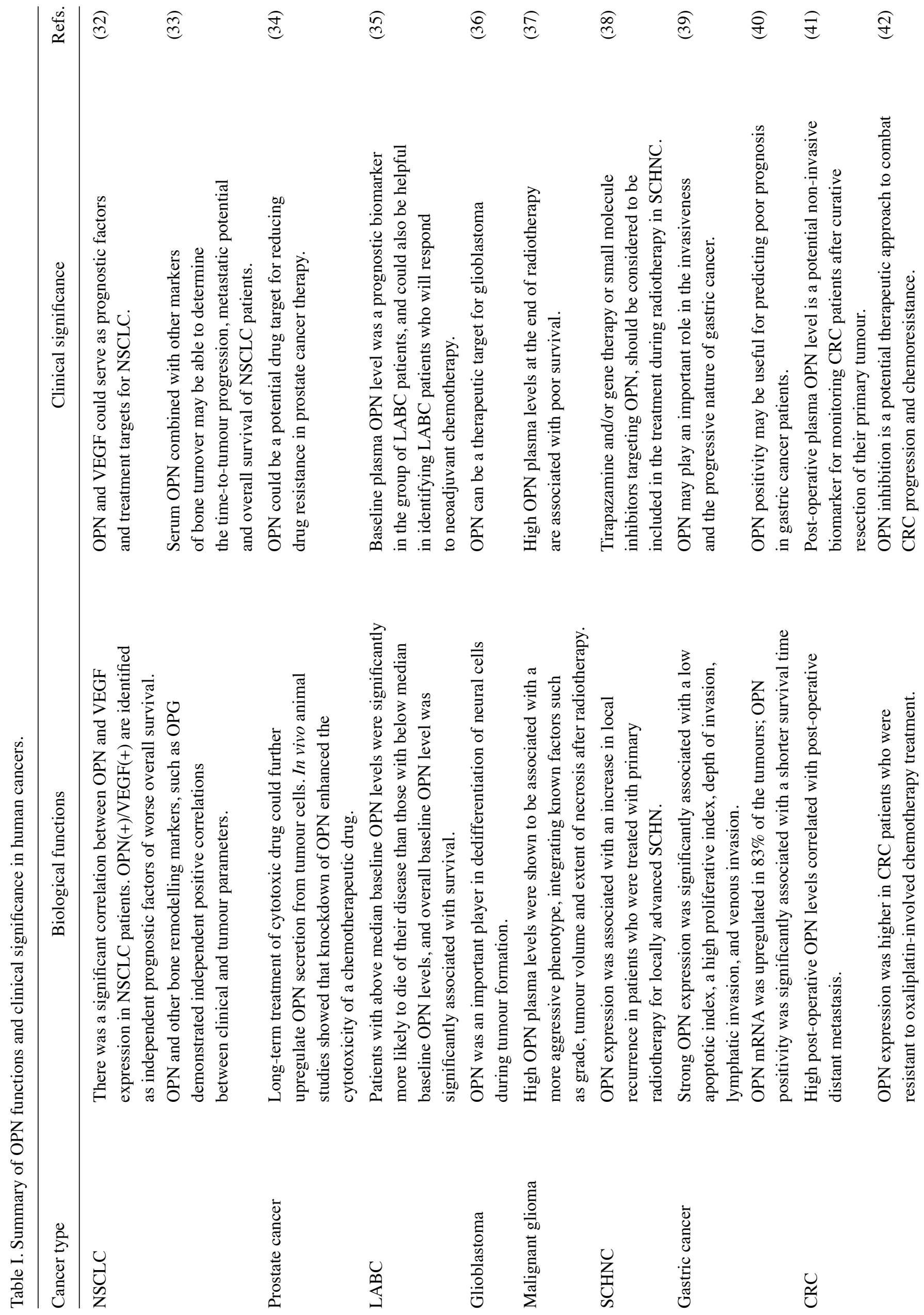




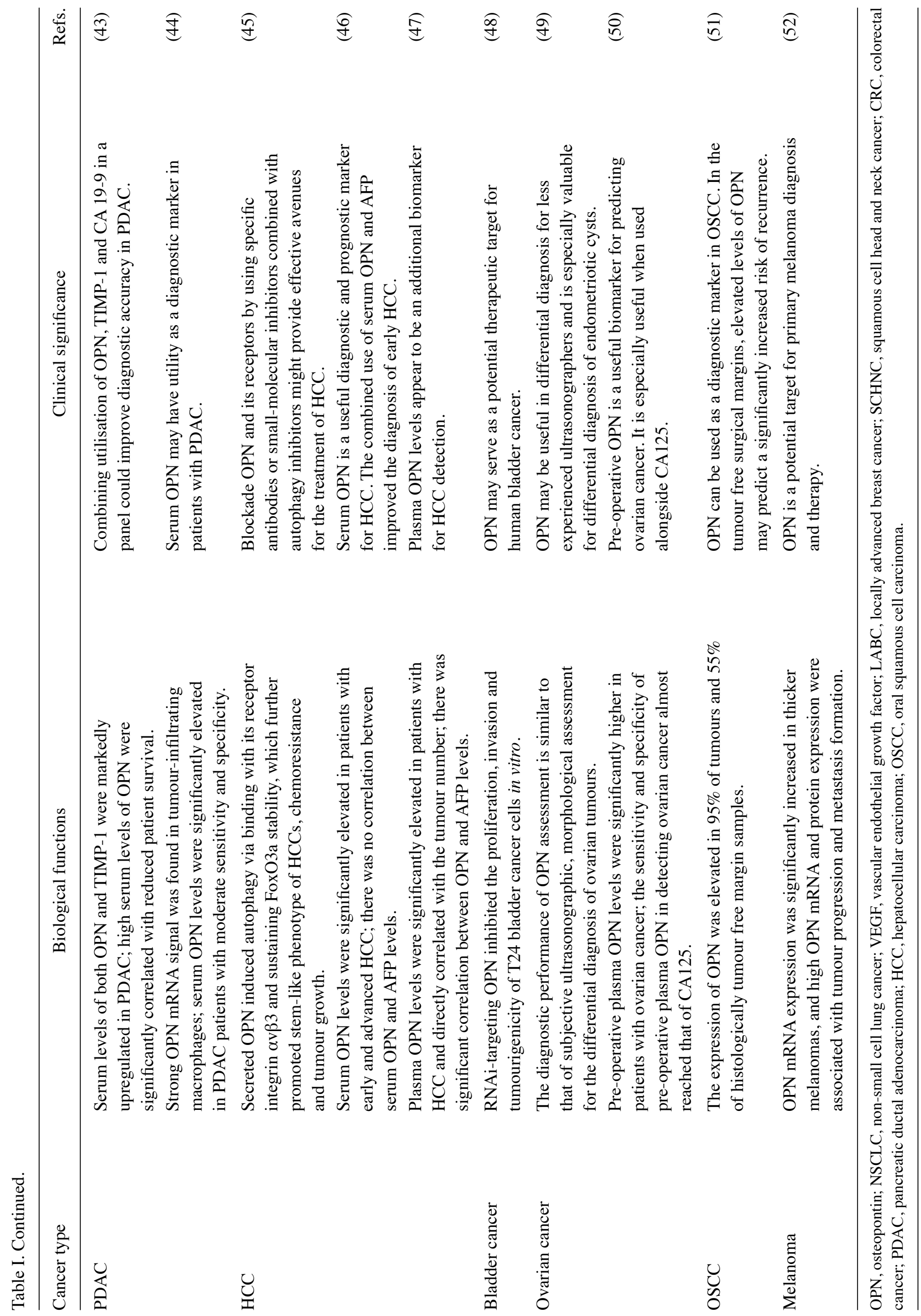


of OPN expression has been identified in a variety of human cancers, including breast, prostate, lung, stomach, pancreatic and colorectal cancer, glioma and melanoma (Table I).

In these studies, in vitro experiments have also established a causal link between OPN expression and cell functions. In vitro transfection experiments have demonstrated that downregulating OPN gene expression suppressed the progression of breast cancer cells, which have invasive potential and metastatic competence (21). Experimental evidence has further suggested that enhanced OPN expression renders a highly metastatic phenotype of cancer cells. For example, the enforced expression of OPN in non-metastatic rat mammary tumour cells has been shown to result in lung metastasis occurring in half of the animals that developed primary tumours (23). In another study, in glioma cells, elevated levels of OPN and VEGF synergistically enhanced the angiogenic properties, via integrin $\alpha v \beta 3$, on the endothelial cell surface (25). Another study demonstrated that the knockdown of OPN in prostate cancer cell lines enhanced the cytotoxicity of the chemotherapeutic drug, daunomycin (DUN), through integrin-mediated FAK/P-GP signalling (34). The ectopic expression of OPN in DLD1 colon cancer cells has been shown to stimulate EMT activation and subsequent migration (41).

In clinical investigations, elevated OPN levels have been shown to correlate with increased tumour burden (stage, grade and tumour size), a poor prognosis and reduced survival, although discrepancies remain. For example, the increased expression of OPN in plasma and tumour tissues has been identified in breast cancer patients and has been shown to be associated with metastatic disease and decreased survival (35). Similarly, in advanced gastric cancer, patients with OPN-positive cancer (as determined by immunohistochemistry) have a decrease in their 5-year survival, when compared with those with OPN-negative cancer (40). In colorectal cancer (CRC) patients, increased OPN mRNA levels have been shown to significantly correlate with stage, lymph node metastasis and lymphatic or venous invasion, as well as with lower disease-free and overall survival rates $(41,42)$. A study on patients with pancreatic ductal adenocarcinoma (PDAC) demonstrated that serum levels of OPN are elevated with advanced tumour grades (44). Elevated OPN levels have also been strongly associated with increased stage, grade and tumour size in melanoma patients (52). In early stage non-small cell lung cancer (NSCLC) patients high OPN plasma levels were observed which were reduced after surgical tumour resection. However, in those patients which showed recurrence after surgery OPN plasma levels re-elevated, indicating that OPN is not only a potential diagnostic marker in NSCLC, but also has potential as a tool for detecting tumour recurrence after treatment (53). Thus, OPN may be a useful biomarker to monitor cancer progression and a significant predictor of poor prognosis and survival rates.

\section{Expression of OPN splice variants in human cancers}

The alternative splice-generation of multiple mRNA products from a single gene is a critical mechanism for generating proteomic diversity. The OPN precusor-mRNA (pre-mRNA) is subject to alternative splicing, which generates three splice variants, OPN-a (consists of all exons), OPN-b (which lacks exon 5) and OPN-c (which lacks exon 4) (Fig. 1).
Recent studies have demonstrated that the expression of OPN splice variants in malignancies is cell-type/tissue specific and may have functional heterogeneity (Table II). For example, Pang et al reported that OPN-c is selectively expressed in breast cancer tissue (57). In their study on 170 breast cancer patients, OPN-c protein staining was positive in $70 \%$ of all of the samples and was significantly higher in tumour tissues compared to normal tissues. The study indicated an inverse correlation between OPN-c and E-cadherin, an established tumour suppressor. However, the observations by the same authors that OPN-c also inversely correlated with $\beta$-catenin and that E-cadherin positively correlated $\beta$-catenin are intriguing. Despite $\beta$-catenin working with E-cadherin to form cell-cell adhesion complexes, $\beta$-catenin has been classically regarded as an oncogenic protein. Thus, the true link between OPN-c and the cell adhesion complex requires further study and one has to delineate the cellular location of $\beta$-catenin (namely membraneassociated, cytoplasmic and nucleus) in this context. However, the study by Pang has clearly demonstrated that high levels of OPN-c staining in breast tumours are associated with TNM staging, nodal involvement, recurrence and metastasis, and interestingly with the triple negativity of the tumours and, thus is an independent prognostic indicator for these patients (57). Another study by Sun et al demonstrated that each of the three OPN splice variants was able to increase the growth of breast tumours, in vivo (56). It is noteworthy that OPN-a appears more effective in promoting tumour growth than the other two splice forms.

Conflicting evidence also exists regarding the function of OPN isoforms in hepatocellular carcinoma (HCC). It has been previously demonstrated that tumour tissue predominantly expressed OPN-a and OPN-b, and the ratio of OPN-a and OPN-b to OPN-c increased substantially as the tumours progressed in SK-Hep1 cells and Hep3B cells (67). Thus, it is possible that OPN-a and OPN-b may be associated with a poor prognosis, and OPN-c may prevent both cell migration and invasion in more migratory and invasive cells. By contrast, in another study, Takafuji et al (68) reported that the increased expression of OPN-c in Hep3B cells appeared to enhance cellular invasion and metastatic potential due to the formation of OPN-c fragment by MMP-9.

A number of studies have also explored OPN splice variants in lung cancer. Sun et al (59) found that, compared with normal lung tissue, the majority of NSCLC samples predominantly expressed OPN-a. A similar observation was made by Blasberg et al (61), who reported that OPN-a was the dominant isoform, whereas little OPN-b and no OPN-c expression was detected in lung cancer cell lines that endogenously expressed OPN (A549, H460, H157, H1299 and Calu-3). Functionally, OPN-a promotes angiogenesis in lung cancer by stimulating endothelial cells, likely by binding to the $\alpha v \beta 3$ integrin and increasing VEGF expression and secretion. In their study, OPN-b appeared to increase tubule formation merely by activating endothelial cells, and did so without a concomitant enhancement of VEGF secretion or expression. OPN-c had a predominantly negative effect significantly inhibiting angiogenesis and VEGF secretion. However, Zhao et al (60) suggested that OPN-b strongly affected cell proliferation, while OPN-c was closely related to the invasive behaviour of the NSCLC cell line, A549. 

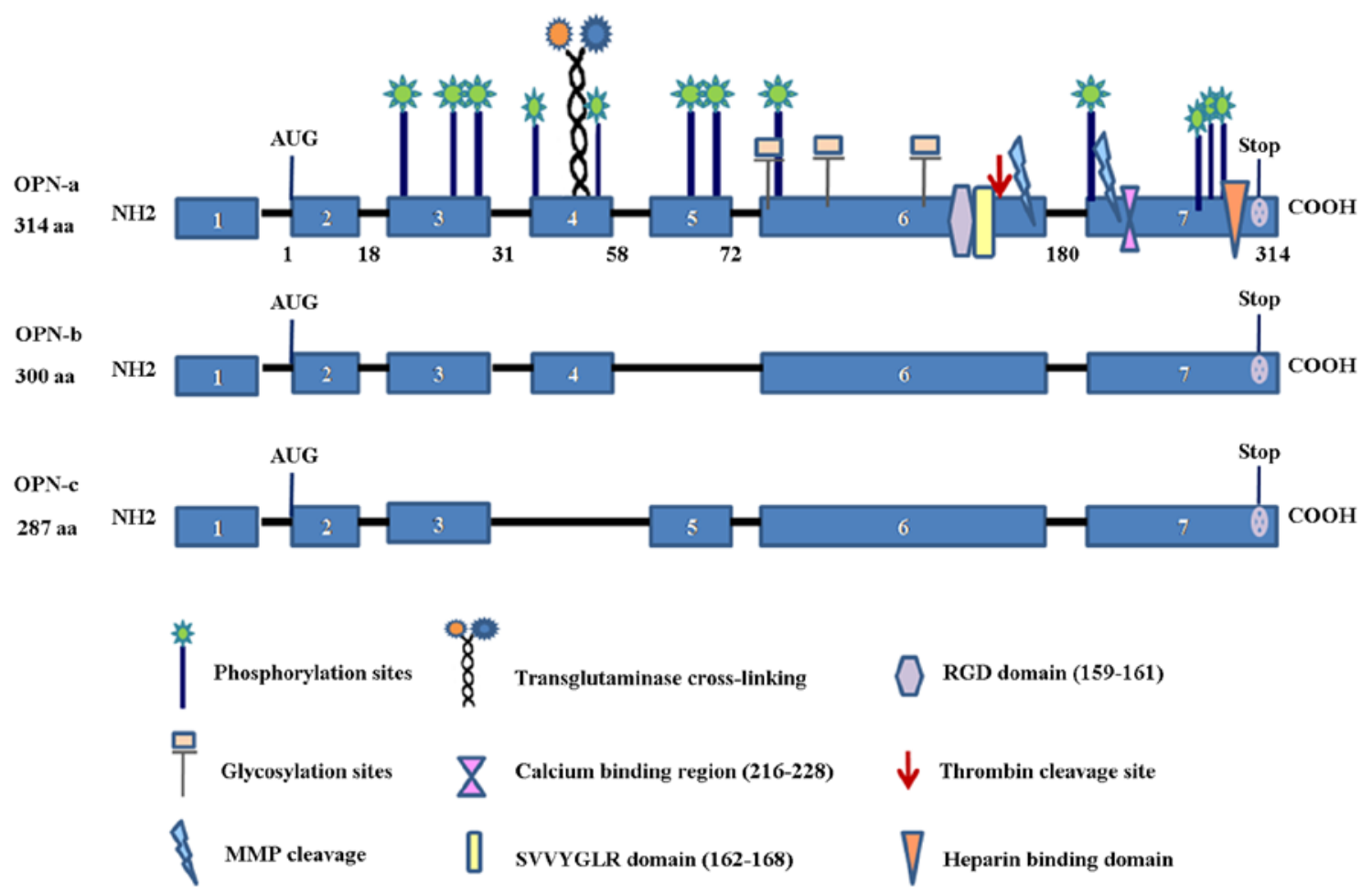

Figure 1. Structural features of the three osteopontin (OPN) splice variants. OPN-a is the full-length isoform with 6 translated exons (314 aa), OPN-b lacks exon 5 (300 aa), and OPN-c lacks exon 4 (287 aa). All OPN variants possess functional domains: arginine-glycine-aspartic acid (RGD) domain (159-161), serine-valine-valine-tyrosine-glutamate-leucine-arginine (SVVYGLR) domain (162-168), thrombin cleavage site, calcium binding domain (216-228) and heparin binding domain. Integrin binding occurs at RGD and SVVYGLR sequences, whilst the CD44 variant receptor binding occurs near the C-terminus. Phosphorylation sites are throughout the whole precusor-mRNA (pre-mRNA). Thrombin cleavage and matrix metalloproteinase (MMP) cleavage sites are present in all three splice variants. Compared with the full-length isoform (OPN-a), OPN-b misses certain phosphorylation sites, while OPN-c is unable to undergo transglutaminase cross-linking. To some extent, the structural differences that exist between the three OPN isoforms may contribute to their clinical and functional differences.

These studies emphasise that OPN splice variants may have diverse expression patterns and different functional roles, which may be cancer type-specific.

\section{Polymorphism of OPN and OPN splice variants in cancers}

Secreted OPN (sOPN) and intracellular OPN (iOPN). OPN has mainly been studied as a secreted protein, but recent studies have shown that, in some cases, OPN is not secreted and instead will be found in the cytoplasm and nucleus. Mouse OPN mRNA has the canonical AUG translation initiation site and an alternative translation initiation site. When translation initiates from the canonical site, the peptide produced is targeted to secretory vesicles. On the other hand, when translation starts from the alternative translation initiation site, the peptide produced is accompanied by deletion of a signal sequence and localises in the cytoplasm $(76,77)$. Although sOPN and iOPN are generated from the same OPN mRNA species, the biological outcomes mediated by the two isoforms may differ (78). The role of human sOPN in cell physiology has been extensively studied in different cellular contexts. Compared with sOPN, the biological roles of iOPN have only begun to emerge over the past several years. Thus far, iOPN has been found in calvarial cells, dendritic cells, macrophages and nerve cells $(77,79,80)$. It is involved in cell motility, cytoskeletal rearrangement and mitosis by physical association with polo-like kinase-1 (Plk-1) (81-83). Similarly, these two isoforms may play distinct roles in cancer progression. Indeed, in patients with various solid tumours, SOPN has been proposed as a diagnostic marker to distinguish either resectable cases or predict survival rates $(43,84,85)$. However, cytoplasmic OPN expression has appeared not to correlate with average tumour size, tumour stage and nodal status $(10,86)$. The same has been observed for OPN splice variants. For example, in a study on expression patterns of OPN variants and its functions on cell apoptosis and invasion in glioma cells, Yan et al presumed that the secretary nature of OPN splice variants may be induced by the absence of exon 5 or exon 4 . As a consequence, OPN-b without out exon 5 may aggregate within the cytoplasm and exert a significant anti-apoptotic effect, while OPN-c without exon 4 may be easily secreted to culture supernatants and has a remarkable effect on cellular invasion (74).

Therefore, it would be necessary to delineate which isoform of OPN is responsible for pathophysiological events, and furthermore, sOPN and iOPN should be independently targeted in any potential therapies.

Host-derived OPN and tumour-derived OPN. Tumour cells and their microenvironment mutually influence tumour formation, progression and metastasis. The tumour microenvironment includes a variety of non-tumour cell types, such as fibroblasts, immune cells, vascular and smooth muscle cells. The host's reaction to neoplastic cells and the ability of environmental modification by tumour cells themselves are both involved in 


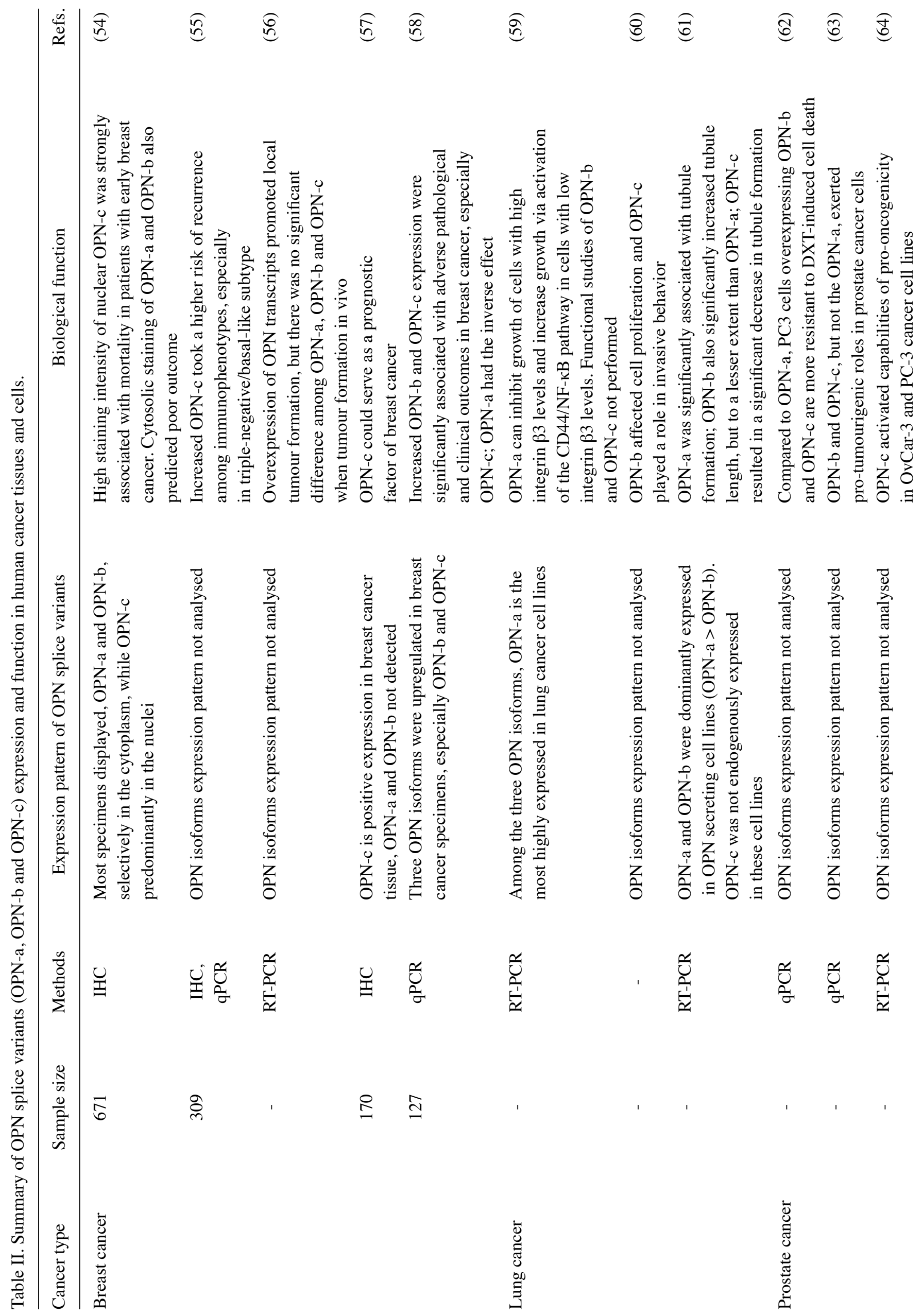




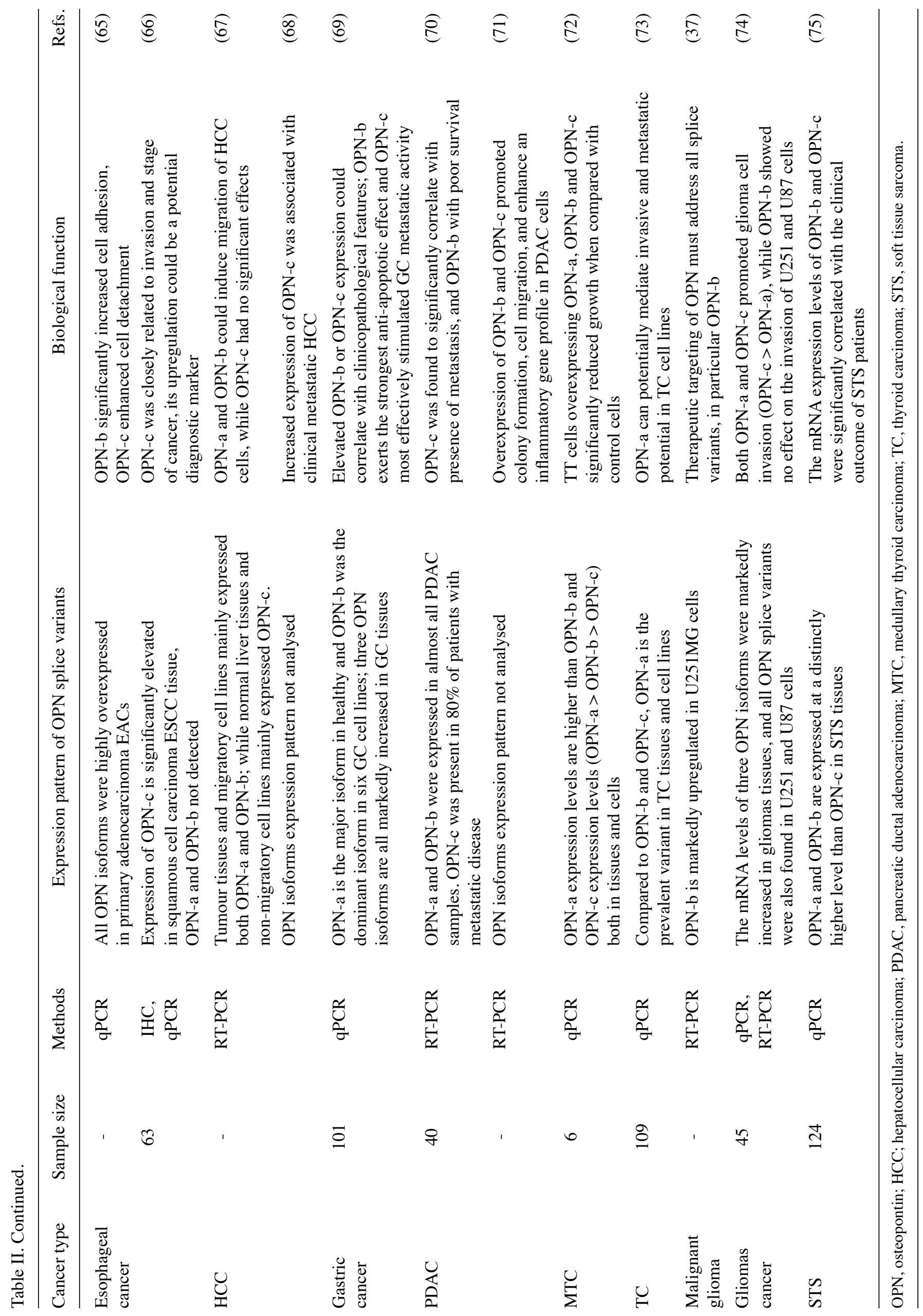


tumour formation. A number of studies have demonstrated that OPN can be synthesised by tumour and other cells types in the tumour microenvironment, such as macrophages and stromal cells $(87,88)$. However, whether tumour-derived OPN differs from host-derived OPN, either structurally or functionally, is largely unknown. There is evidence indicating that the role of OPN in metastasis is dependent on the site of production. For example, historically, stroma-derived OPN has been considered to be intrinsically involved in the defensive mechanism against tumour development by acting as a macrophage chemoattractant, yet stroma-derived OPN can effectively regulate melanoma growth, angiogenesis and metastasis with the host OPN-tumour interaction (89-91). In addition, tumour-derived OPN may promote the metastatic process by inhibiting macrophage cytotoxicity against tumours (92). By contrast, some evidence suggests that at least in some instances, the presence of OPN in macrophages promote the development and activity of type I natural killer (NK) T cells (NK T cells) and that OPN may inhibit tumour activity via these NK cells (93).

Thus, host-derived OPN and tumour-derived OPN may mutually affect each other and the interaction between the tumour and tumour microenvironment may determine whether the overall effect of OPN will be tumour promoting or tumour inhibiting.

OPN splice variants polymorphism in cancers. The similar heterogeneity of OPN splice variants exists in cancers. the differential effects of the three splice variants may be due to the distinctive functions of the spliced exons that individual OPN isoforms contain. For example, the sequences encoded by exon 5, absent in OPN-b, contain one of several clusters of phosphorylated serine/threonine residues. Exon 4 however encodes two glutamine residues essential for transglutaminase crosslinking. As exon 4 is absent in OPN-c, but present in OPN-a and OPN-b, OPN-c has no specific functions exerted by exon 4 (94). In breast cancer cells, it has been reported that OPN-a, not OPN-c may have a tendency to aggregate in response to physical concentrations of calcium, and thus have a greater capacity to enhance cell adhesion (95). By contrast, OPN-c may be more soluble and able to support anchorage-independent growth of breast cancer cells $(96,97)$. OPN-c possesses a more exposed Arg-Ser-Lys (RSK) motif compared to OPN-a (98). Using the RSK motif as a cleavage site, systemically circulating thrombin can cleave OPN-c easily into two fragments, the N-terminal and C-terminal, of approximately equivalent size (98). The $\mathrm{N}$-terminal GRGDS-containing fragment produced by thrombin cleavage has the potential to enhance tumour cell migration (98). The thrombin-cleaved C-terminal fragment of OPN has also been reported to influence breast cancer cell migration and invasion in vitro (99). The absence of the transglutaminase acting site in OPN-c may explain why OPN-c cannot be crosslinked with the extracellular matrix (94).

On the other hand, some investigations suggest that the possible reasons for OPN isoforms cell-type specific patterns and their roles are closely related to these differing PTMs of the three OPN splice variants. Gimba et al demonstrated that the potential of OPN-a, OPN-b and OPN-c for specific phosphorylation patterns, and the deletion of exon 4 or 5 altered the pattern of PTMs, ultimately resulting in functional modifications (46).

\section{Conclusion and future perspectives}

OPN was initially identified in bone and later characterised based on its splice variants and their structures and functions. It is now well established that the isoforms of OPN are differentially expressed in many tumour types and play critical roles at different stages of cancer development and progression. OPN may be a useful biomarker to monitor cancer progression and one of the significant predictors of poor prognosis and survival rates, in certain cancers for example in breast cancer and lung cancer. Thus, OPN may have several potential clinical implications: firstly, as a convenient tool for clinical test. As a secreted protein, OPN can easily detected in body fluids, such as blood, urine and body cavity fluids (namely pleural and peritoneal ascites). This gives rise to convenient sampling, taking advantages of sample quantity, safe detection, procedure speed and minimal invasiveness, collectively providing a convenient approach for clinical testing. Secondly, the power of combining OPN with other traditional biomarkers, such as VEGF, MMPs and E-cadherin, for example, provide more accurate predictions for prognosis and potential response to therapies $(43,50,100)$.

Yet, changes remain, especially given the complexity of the distribution patterns and presence of the variant forms for OPN. Methods of OPN detection are currently very limited. Traditional protein detection methods such as ELISA have shown their limit due to a lack of sensitivity and the nature of samples required for the testings. Several studies have focused on the cost-effectiveness and ease of implementing immunosensors for OPN detection demonstrating better sensitivity than ELISA assays, and providing greater potential to develop simple test kits for OPN combined with other protein biomarkers (101-104).

Due to the pre- and post-translational regulation, the expression and function patterns of OPN isoforms usually exhibit tissue specificity. It has been suggested that this provides the possibility to develop cancer therapy strategies to target those OPN isoforms which are specific to tumour cells or play a key role in tumour progression. But the pre- and post-translational regulation are complex and ubiquitous, developing drugs that target only cancer cells with minimal impact on healthy cells is extremely difficult. Thus the expression patterns and activities of tumour-specific OPN isoforms should be further defined with multidisciplinary and large scale clinical study. The development of specific OPN-based approaches for individual cancer types is equally important as well.

Collectively, OPN and its variants have been shown to play an important role in regulating the aggressive nature of cancer cells and promote the growth of tumours. Although there is more to learn with regards to the mechanisms of action of the specific OPN variants, it is clear that there is clinical prospect(s) for this protein and its variants. OPN appears to have good clinical value in evaluating disease progression and cancer patient outcome. There is a good prospect for developing a OPN based clinical test for cancer patients in order to evaluate their prognosis and response to therapies. Wht is most exciting is the prospect of developing tools to target the protein and its variants in novel ways. It is anticipated that in the coming years we will see some significant progress along these fronts. 


\section{Acknowledgements}

The authors wish to thank Cancer Research Wales, Cardiff University China Medical Scholarship, Life Science Research Network for Wales (LSRNW) and the Albert Hung Foundation for supporting their study.

\section{References}

1. Giachelli CM, Liaw L, Murry CE, Schwartz SM and Almeida M: Osteopontin expression in cardiovascular diseases. Ann NY Acad Sci 760: 109-126, 1995.

2. Weber GF and Cantor H: The immunology of Eta-1/osteopontin. Cytokine Growth Factor Rev 7: 241-248, 1996.

3. Denhardt DT and Noda M: Osteopontin expression and function: role in bone remodeling. J Cell Biochem Suppl 30-31 (S30-31): 92-102, 1998.

4. Sodek J, Ganss B and McKee MD: Osteopontin. Crit Rev Oral Biol Med 11: 279-303, 2000.

5. Christensen B, Kazanecki CC, Petersen TE, Rittling SR, Denhardt DT and Sørensen ES: Cell type-specific post-translational modifications of mouse osteopontin are associated with different adhesive properties. J Biol Chem 282: 19463-19472, 2007.

6. Christensen B, Nielsen MS, Haselmann KF, Petersen TE and Sørensen ES: Post-translationally modified residues of native human osteopontin are located in clusters: identification of 36 phosphorylation and five O-glycosylation sites and their biological implications. Biochem J 390: 285-292, 2005.

7. Christensen B, Petersen TE and Sørensen ES: Post-translational modification and proteolytic processing of urinary osteopontin. Biochem J 411: 53-61, 2008.

8. Denhardt DT and Guo X: Osteopontin: a protein with diverse functions. FASEB J 7: 1475-1482, 1993

9. Cho HJ, Cho HJ and Kim HS: Osteopontin: a multifunctional protein at the crossroads of inflammation, atherosclerosis, and vascular calcification. Curr Atheroscler Rep 11: 206-213, 2009.

10. Coppola D, Szabo M, Boulware D, Muraca P, Alsarraj M, Chambers AF and Yeatman TJ: Correlation of osteopontin protein expression and pathological stage across a wide variety of tumor histologies. Clin Cancer Res 10: 184-190, 2004.

11. Rittling SR and Chambers AF: Role of osteopontin in tumour progression. Br J Cancer 90: 1877-1881, 2004

12. El-Tanani MK, Campbell FC, Kurisetty V, Jin D, McCann M and Rudland PS: The regulation and role of osteopontin in malignant transformation and cancer. Cytokine Growth Factor Rev 17: 463-474, 2006.

13. Bellahcène A, Castronovo V, Ogbureke KU, Fisher LW and Fedarko NS: Small integrin-binding ligand N-linked glycoproteins (SIBLINGs): multifunctional proteins in cancer. Nat Rev Cancer 8: 212-226, 2008.

14. Smith LL, Cheung HK, Ling LE, Chen J, Sheppard D, Pytela R and Giachelli CM: Osteopontin N-terminal domain contains a cryptic adhesive sequence recognized by alpha9betal integrin. $\mathrm{J}$ Biol Chem 271: 28485-28491, 1996.

15. Yokosaki Y, Matsuura N, Sasaki T, Murakami I, Schneider H, Higashiyama S, Saitoh Y, Yamakido M, Taooka Y and Sheppard D: The integrin alpha(9)beta(1) binds to a novel recognition sequence (SVVYGLR) in the thrombin-cleaved amino-terminal fragment of osteopontin. J Biol Chem 274: 36328-36334, 1999

16. Scatena M, Liaw L and Giachelli CM: Osteopontin: a multifunctional molecule regulating chronic inflammation and vascular disease. Arterioscler Thromb Vasc Biol 27: 2302-2309, 2007.

17. Sun BS, Li Y, Zhang ZF, You J and Wang CL: Osteopontin combined with CD44v6, a novel prognostic biomarker in non-small cell lung cancer undergoing curative resection. Ann Thorac Surg 96: 1943-1951, 2013.

18. Gao YL, Xing LQ, Ren TJ, Hou JF, Xue Q, Liu C and Han YM: The expression of osteopontin in breast cancer tissue and its relationship with p21ras and CD44V6 expression. Eur J Gynaecol Oncol 37: 41-47, 2016

19. Yang L, Shang X, Zhao X, Lin Y and Liu J: Correlation study between OPN, CD44v6, MMP-9 and distant metastasis in laryngeal squamous cell carcinoma. Lin Chung Er Bi Yan Hou Tou Jing Wai Ke Za Zhi 26: 989-992, 2012 (In Chinese).
20. Kim JS, Bashir MM and Werth VP: Gottron's papules exhibit dermal accumulation of CD44 variant 7 (CD44v7) and its binding partner osteopontin: a unique molecular signature. J Invest Dermatol 132: 1825-1832, 2012.

21. Allan AL, George R, Vantyghem SA, Lee MW, Hodgson NC, Engel CJ, Holliday RL, Girvan DP, Scott LA, Postenka CO, et al: Role of the integrin-binding protein osteopontin in lymphatic metastasis of breast cancer. Am J Pathol 169: 233-246, 2006.

22. Courter D, Cao H, Kwok S, Kong C, Banh A, Kuo P, Bouley DM Vice C, Brustugun OT, Denko NC, et al: The RGD domain of human osteopontin promotes tumor growth and metastasis through activation of survival pathways. PLoS One 5: e9633, 2010.

23. Cui R, Takahashi F, Ohashi R, Gu T, Yoshioka M, Nishio K, Ohe Y, Tominaga S, Takagi Y, Sasaki S, et al: Abrogation of the interaction between osteopontin and alphavbeta3 integrin reduces tumor growth of human lung cancer cells in mice. Lung Cancer 57: 302-310, 2007.

24. Wu CM, Chen PC, Li TM, Fong YC and Tang CH: Si-Wu-tang extract stimulates bone formation through PI $3 \mathrm{~K} / \mathrm{Akt} / \mathrm{NF}-\kappa \mathrm{B}$ signaling pathways in osteoblasts. BMC Complement Altern Med 13: 277, 2013.

25. Wang Y, Yan W, Lu X, Qian C, Zhang J, Li P, Shi L, Zhao P, Fu Z, $\mathrm{Pu} \mathrm{P}$, et al: Overexpression of osteopontin induces angiogenesis of endothelial progenitor cells via the av $\beta 3 / \mathrm{PI} 3 \mathrm{~K} / \mathrm{AKT} / \mathrm{eNOS} / \mathrm{NO}$ signaling pathway in glioma cells. Eur J Cell Biol 90: 642-648, 2011.

26. Ogata T, Ueyama T, Nomura T, Asada S, Tagawa M, Nakamura T, Takahashi T, Matsubara $\mathrm{H}$ and $\mathrm{Oh} \mathrm{H}$ : Osteopontin is a myosphere-derived secretory molecule that promotes angiogenic progenitor cell proliferation through the phosphoinositide 3-kinase/ Akt pathway. Biochem Biophys Res Commun 359: 341-347, 2007.

27. Chen RX, Xia YH,Xue TC,Zhang H and Ye SL: Down-regulation of osteopontin inhibits metastasis of hepatocellular carcinoma cells via a mechanism involving MMP-2 and uPA. Oncol Rep 25: 803-808, 2011.

28. Mi Z, Guo H, Wai PY, Gao C and Kuo PC: Integrin-linked kinase regulates osteopontin-dependent MMP-2 and uPA expression to convey metastatic function in murine mammary epithelial cancer cells. Carcinogenesis 27: 1134-1145, 2006.

29. Tuck AB, Hota C and Chambers AF: Osteopontin(OPN)-induced increase in human mammary epithelial cell invasiveness is urokinase (uPA)-dependent. Breast Cancer Res Treat 70: 197-204, 2001

30. Kerenidi T, Kazakou AP, Lada M, Tsilioni I, Daniil Z and Gourgoulianis KI: Clinical significance of circulating osteopontin levels in patients with lung cancer and correlation with VEGF and MMP-9. Cancer Invest 34: 385-392, 2016.

31. Babarović E, Valković T, Budisavljević I, Balen I, Štifter S, Duletić-Načinović A, Lučin K and Jonjić N: The expression of osteopontin and vascular endothelial growth factor in correlation with angiogenesis in monoclonal gammopathy of undetermined significance and multiple myeloma. Pathol Res Pract 212: 509-516, 2016.

32. Lin Q, Guo L, Lin G, Chen Z, Chen T, Lin J, Zhang B and $\mathrm{Gu} \mathrm{X}$ : Clinical and prognostic significance of OPN and VEGF expression in patients with non-small-cell lung cancer. Cancer Epidemiol 39: 539-544, 2015.

33. Terpos E, Kiagia M, Karapanagiotou EM, Charpidou A, Dilana KD, Nasothimiou E, Harrington KJ, Polyzos A and Syrigos KN: The clinical significance of serum markers of bone turnover in NSCLC patients: surveillance, management and prognostic implications. Anticancer Res 29: 1651-1657, 2009.

34. Hsieh IS, Huang WH, Liou HC, Chuang WJ, Yang RS and Fu WM: Upregulation of drug transporter expression by osteopontin in prostate cancer cells. Mol Pharmacol 83: 968-977, 2013.

35. Anborgh PH, Caria LB, Chambers AF, Tuck AB, Stitt LW and Brackstone M: Role of plasma osteopontin as a biomarker in locally advanced breast cancer. Am J Transl Res 7: 723-732, 2015.

36. Friedmann-Morvinski D, Bhargava V, Gupta S, Verma IM and Subramaniam S: Identification of therapeutic targets for glioblastoma by network analysis. Oncogene 35: 608-620, 2016

37. Güttler A, Giebler M, Cuno P, Wichmann H, Keßler J, Ostheimer C, Söling A, Strauss C, Illert J, Kappler M, et al: Osteopontin and splice variant expression level in human malignant glioma: radiobiologic effects and prognosis after radiotherapy. Radiother Oncol 108: 535-540, 2013 
38. Etiz D, Ataizi FC, Bayman E, Akcay M, Acikalin MF, Colak E and Ciftci E: Prognostic value of osteopontin in patients treated with primary radiotherapy for head and neck cancer. Asian Pac J Cancer Prev 14: 5175-5178, 2013.

39. Imano M, Satou T, Itoh T, Sakai K, IshimaruE, Yasuda A, Peng YF, Shinkai M, Akai F, Yasuda T, et al: Immunohistochemical expression of osteopontin in gastric cancer. J Gastrointest Surg 13: 1577-1582, 2009.

40. Higashiyama M, Ito T, Tanaka E and Shimada Y: Prognostic significance of osteopontin expression in human gastric carcinoma. Ann Surg Oncol 14: 3419-3427, 2007.

41. Ng L, Wan TM, Lam CS, Chow AK, Wong SK, Man JH, Li HS, Cheng NS, Pak RC, Cheung AH, et al: Post-operative plasma osteopontin predicts distant metastasis in human colorectal cancer. PLoS One 10: e0126219, 2015.

42. Ng L, Wan T, Chow A, Iyer D, Man J, Chen G, Yau TC, Lo O, Foo CC, Poon JT, et al: Osteopontin overexpression induced tumor progression and chemoresistance to oxaliplatin through induction of stem-like properties in human colorectal cancer. Stem Cells Int 2015: 247892, 2015.

43. Poruk KE, Firpo MA, Scaife CL, Adler DG, Emerson LL, Boucher KM and Mulvihill SJ: Serum osteopontin and tissue inhibitor of metalloproteinase 1 as diagnostic and prognostic biomarkers for pancreatic adenocarcinoma. Pancreas 42: 193-197, 2013.

44. Koopmann J,Fedarko NS, Jain A,Maitra A,Iacobuzio-Donahue C, Rahman A, Hruban RH, Yeo CJ and Goggins M: Evaluation of osteopontin as biomarker for pancreatic adenocarcinoma. Cancer Epidemiol Biomarkers Prev 13: 487-491, 2004

45. Liu G, Fan X, Tang M, Chen R, Wang H, Jia R, Zhou X, Jing W, Wang H, Yang Y, et al: Osteopontin induces autophagy to promote chemo-resistance in human hepatocellular carcinoma cells. Cancer Lett 383: 171-182, 2016.

46. Gimba ER and Tilli TM: Human osteopontin splicing isoforms: known roles, potential clinical applications and activated signaling pathways. Cancer Lett 331: 11-17, 2013.

47. Salem M, Atti SA, Raziky ME, Darweesh SK and Sharkawy ME: Clinical significance of plasma osteopontin level as a biomarker of hepatocellular carcinoma. Gastroenterology Res 6: 191-199, 2013.

48. Xu ST, Guo C, Ding X, Fan WJ, Zhang FH, Xu WL and Ma YC: Role of osteopontin in the regulation of human bladder cancer proliferation and migration in T24 cells. Mol Med Rep 11: 3701-3707, 2015.

49. Moszynski R, Szubert S, Szpurek D, Michalak S and Sajdak S: Role of osteopontin in differential diagnosis of ovarian tumors. J Obstet Gynaecol Res 39: 1518-1525, 2013.

50. Nakae M, Iwamoto I, Fujino T, Maehata Y, Togami S, Yoshinaga $\mathrm{M}$ and Douchi T: Preoperative plasma osteopontin level as a biomarker complementary to carbohydrate antigen 125 in predicting ovarian cancer. J Obstet Gynaecol Res 32: 309-314, 2006.

51. Subramani VN, Narasimhan M, Thiyagarajan M, Munuswamy BD and Jayamani L: Expression of osteopontin in oral squamous cell carcinoma and its surgical margins-an immunohistochemical study. J Clin Diagn Res 9: ZC66-ZC69, 2015.

52. Kiss T, Ecsedi S, Vizkeleti L, Koroknai V, Emri G, Kovács N, Adany R and Balazs M: The role of osteopontin expression in melanoma progression. Tumour Biol 36: 7841-7847, 2015.

53. Blasberg JD, Pass HI, Goparaju CM, Flores RM, Lee S and Donington JS: Reduction of elevated plasma osteopontin levels with resection of non-small-cell lung cancer. J Clin Oncol 28: 936-941, 2010

54. Zduniak K, Ziolkowski P, Ahlin C, Agrawal A, Agrawal S, Blomqvist C, Fjällskog ML and Weber GF: Nuclear osteopontin-c is a prognostic breast cancer marker. Br J Cancer 112: 729-738, 2015.

55. Ortiz-Martínez F, Perez-Balaguer A, Ciprián D, Andrés L, Ponce J, Adrover E, Sánchez-Payá J, Aranda FI, Lerma E and Peiró G: Association of increased osteopontin and splice variant-c mRNA expression with HER2 and triple-negative/basal-like breast carcinomas subtypes and recurrence. Hum Pathol 45: 504-512, 2014

56. Sun J, Feng A, Chen S, Zhang Y, Xie Q, Yang M, Shao Q, Liu J, Yang Q, Kong B, et al: Osteopontin splice variants expressed by breast tumors regulate monocyte activation via MCP-1 and TGF-ß1. Cell Mol Immunol 10: 176-182, 2013.

57. Pang H, Lu H, Song H, Meng Q, Zhao Y, Liu N, Lan F, Liu Y, Yan S, Dong X, et al: Prognostic values of osteopontin-c, E-cadherin and $\beta$-catenin in breast cancer. Cancer Epidemiol 37: 985-992, 2013.
58. Patani N, Jouhra F, Jiang W and Mokbel K: Osteopontin expression profiles predict pathological and clinical outcome in breast cancer. Anticancer Res 28: 4105-4110, 2008.

59. Sun SJ, Wu CC, Sheu GT, Chang HY, Chen MY, Lin YY, Chuang CY, Hsu SL and Chang JT: Integrin $\beta 3$ and CD44 levels determine the effects of the OPN-a splicing variant on lung cancer cell growth. Oncotarget 7: 55572-55584, 2016.

60. Zhao B, Sun T, Meng F, Qu A, Li C, Shen H, Jin Y and Li W: Osteopontin as a potential biomarker of proliferation and invasiveness for lung cancer. J Cancer Res Clin Oncol 137: 1061-1070, 2011.

61. Blasberg JD, Goparaju CM, Pass HI and Donington JS: Lung cancer osteopontin isoforms exhibit angiogenic functional heterogeneity. J Thorac Cardiovasc Surg 139: 1587-1593, 2010.

62. Nakamura KD, Tilli TM, Wanderley JL, Palumbo A Jr, Mattos RM, Ferreira AC, Klumb CE4, Nasciutti LE and Gimba ER: Osteopontin splice variants expression is involved on docetaxel resistance in PC3 prostate cancer cells. Tumour Biol 37: 2655-2663, 2016.

63. Tilli TM, Bellahcène A, Castronovo V and Gimba ER: Changes in the transcriptional profile in response to overexpression of the osteopontin-c splice isoform in ovarian (OvCar-3) and prostate (PC-3) cancer cell lines. BMC Cancer 14: 433, 2014.

64. Tilli TM, Mello KD, Ferreira LB, Matos AR, Accioly MT, Faria PA, Bellahcène A, Castronovo V and Gimba ER: Both osteopontin-c and osteopontin-b splicing isoforms exert pro-tumorigenic roles in prostate cancer cells. Prostate 72: 1688-1699, 2012

65. Lin J, Myers AL, Wang Z, Nancarrow DJ, Ferrer-Torres D, Handlogten A, Leverenz K, Bao J, Thomas DG, Wang TD, et al: Osteopontin (OPN/SPP1) isoforms collectively enhance tumor cell invasion and dissemination in esophageal adenocarcinoma. Oncotarget 6: 22239-22257, 2015.

66. Zhang MX, Xu YJ, Zhu MC and Yan F: Overexpressed ostepontin-c as a potential biomarker for esophageal squamous cell carcinoma. Asian Pac J Cancer Prev 14: 7315-7319, 2013.

67. Chae S, Jun HO, Lee EG, Yang SJ, Lee DC, Jung JK, Park KC, Yeom YI and Kim KW: Osteopontin splice variants differentially modulate the migratory activity of hepatocellular carcinoma cell lines. Int J Oncol 35: 1409-1416, 2009.

68. Takafuji V, Forgues M, Unsworth E, Goldsmith P and Wang XW: An osteopontin fragment is essential for tumor cell invasion in hepatocellular carcinoma. Oncogene 26: 6361-6371, 2007.

69. Tang X, Li J, Yu B, Su L, Yu Y, Yan M, Liu B and Zhu Z: Osteopontin splice variants differentially exert clinicopathological features and biological functions in gastric cancer. Int J Biol Sci 9: 55-66, 2013.

70. Siddiqui AA, Jones E, Andrade D, Shah A, Kowalski TE, Loren DE, Chipitsyna G and Arafat HA: Osteopontin splice variant as a potential marker for metastatic disease in pancreatic adenocarcinoma. J Gastroenterol Hepatol 29: 1321-1327, 2014.

71. Sarosiek K, Jones E, Chipitsyna G, Al-Zoubi M, Kang C, Saxena S, Gandhi AV, Sendiky J, Yeo CJ and Arafat HA: Osteopontin (OPN) isoforms, diabetes, obesity, and cancer; what is one got to do with the other? A new role for OPN. J Gastrointest Surg 19: 639-650, 2015.

72. Ferreira LB, Eloy C, Pestana A, Lyra J, Moura M, Prazeres H, Tavares C, Sobrinho-Simões M, Gimba E and Soares P: Osteopontin expression is correlated with differentiation and good prognosis in medullary thyroid carcinoma. Eur $\mathbf{J}$ Endocrinol 174: 551-561, 2016.

73. Ferreira LB, Tavares C, Pestana A, Pereira CL, Eloy C, Pinto MT, Castro P, Batista R, Rios E, Sobrinho-Simões M, et al: Osteopontin-a splice variant is overexpressed in papillary thyroid carcinoma and modulates invasive behavior. Oncotarget 7: 52003-52016, 2016.

74. Yan W, Qian C, Zhao P, Zhang J, Shi L, Qian J, Liu N, Fu Z, Kang C, Pu P, et al: Expression pattern of osteopontin splice variants and its functions on cell apoptosis and invasion in glioma cells. Neuro-oncol 12: 765-775, 2010.

75. Hahnel A, Wichmann H, Greither T, Kappler M, Würl P, Kotzsch M, Taubert H, Vordermark D and Bache M: Prognostic impact of mRNA levels of osteopontin splice variants in soft tissue sarcoma patients. BMC Cancer 12: 131, 2012.

76. Inoue $M$ and Shinohara ML: Intracellular osteopontin (iOPN) and immunity. Immunol Res 49: 160-172, 2011.

77. Shinohara ML, Kim HJ, Kim JH, Garcia VA and Cantor H: Alternative translation of osteopontin generates intracellular and secreted isoforms that mediate distinct biological activities in dendritic cells. Proc Natl Acad Sci USA 105: 7235-7239, 2008. 
78. Yushi Q, Li Z, Von Roemeling CA, Doeppler H, Marlow LA, Kim BY, Radisky DC, Storz P, Copland JA and Tun HW Osteopontin is a multi-faceted pro-tumorigenic driver for central nervous system lymphoma. Oncotarget 7: 32156-32171, 2016

79. Zohar R, Lee W, Arora P, Cheifetz S, McCulloch C and Sodek J: Single cell analysis of intracellular osteopontin in osteogenic cultures of fetal rat calvarial cells. J Cell Physiol 170: 88-100, 1997.

80. Zhao W, Wang L, Zhang L, Yuan C, Kuo PC and Gao C: Differential expression of intracellular and secreted osteopontin isoforms by murine macrophages in response to toll-like receptor agonists. J Biol Chem 285: 20452-20461, 2010.

81. Junaid A, Moon MC, Harding GE and Zahradka P: Osteopontin localizes to the nucleus of 293 cells and associates with polo-like kinase-1. Am J Physiol Cell Physiol 292: C919-C926, 2007.

82. Zohar R, Suzuki N, Suzuki K, Arora P, Glogauer M, McCulloch CA and Sodek J: Intracellular osteopontin is an integral component of the CD44-ERM complex involved in cell migration. J Cell Physiol 184: 118-130, 2000.

83. Shinohara ML, Lu L, Bu J, Werneck MB, Kobayashi KS Glimcher LH and Cantor H: Osteopontin expression is essential for interferon-alpha production by plasmacytoid dendritic cells Nat Immunol 7: 498-506, 2006.

84. Chen R, Crispin DA, Pan S, Hawley S, McIntosh MW, May D, Anton-Culver H, Ziogas A, Bronner MP and Brentnall TA: Pilot study of blood biomarker candidates for detection of pancreatic cancer. Pancreas 39: 981-988, 2010.

85. Fedarko NS, Jain A, Karadag A, Van Eman MR and Fisher LW: Elevated serum bone sialoprotein and osteopontin in colon, breast, prostate, and lung cancer. Clin Cancer Res 7: 4060-4066, 2001.

86. Collins AL, Rock J, Malhotra L, Frankel WL and Bloomston M: Osteopontin expression is associated with improved survival in patients with pancreatic adenocarcinoma. Ann Surg Oncol 19: 2673-2678, 2012.

87. Ashkar S, Weber GF, Panoutsakopoulou V, Sanchirico ME, Jansson M, Zawaideh S, Rittling SR, Denhardt DT, Glimcher MJ and Cantor H: Eta-1 (osteopontin): an early component of type-1 (cell-mediated) immunity. Science 287: 860-864, 2000.

88. Chan SC, Tekari A, Benneker LM, Heini PF and Gantenbein B: Osteogenic differentiation of bone marrow stromal cells is hindered by the presence of intervertebral disc cells. Arthritis Res Ther 18: 29, 2015.

89. Kumar S, Sharma P, Kumar D, Chakraborty G, Gorain M and Kundu GC: Functional characterization of stromal osteopontin in melanoma progression and metastasis. PLoS One 8: e69116, 2013.

90. Chen JJ, Lin YC, Yao PL, Yuan A, Chen HY, Shun CT, Tsai MF, Chen $\mathrm{CH}$ and Yang PC: Tumor-associated macrophages: the double-edged sword in cancer progression. J Clin Oncol 23: 953-964, 2005

91. Zhu XD, Zhang JB, Zhuang PY, Zhu HG, Zhang W, Xiong YQ, Wu WZ, Wang L, Tang ZY and Sun HC: High expression of macrophage colony-stimulating factor in peritumoral liver tissue is associated with poor survival after curative resection of hepatocellular carcinoma. J Clin Oncol 26: 2707-2716, 2008.

92. Wai PY, Guo L, Gao C, Mi Z, Guo H and Kuo PC: Osteopontin inhibits macrophage nitric oxide synthesis to enhance tumor proliferation. Surgery 140: 132-140, 2006.
93. Sato K, Iwai A, Nakayama Y, Morimoto J, Takada A, Maruyama M, Kida H, Uede T and Miyazaki T: Osteopontin is critical to determine symptom severity of influenza through the regulation of NK cell population. Biochem Biophys Res Commun 417: 274-279, 2012 .

94. Collighan RJ and Griffin M: Transglutaminase 2 cross-linking of matrix proteins: biological significance and medical applications. Amino Acids 36: 659-670, 2009.

95. He B, Mirza M and Weber GF: An osteopontin splice variant induces anchorage independence in human breast cancer cells Oncogene 25: 2192-2202, 2006.

96. Shen H and Weber GF: The osteopontin-c splice junction is important for anchorage-independent growth. Mol Carcinog 53: 480-487, 2014.

97. Shi Z, Wang B, Chihanga T, Kennedy MA and Weber GF: Energy metabolism during anchorage-independence. Induction by osteopontin-c. PLoS One 9: e105675, 2014.

98. Sivakumar S and Niranjali Devaraj S: Tertiary structure prediction and identification of druggable pocket in the cancer biomarker - osteopontin-c. J Diabetes Metab Disord 13: 13, 2014

99. Mi Z, Oliver T, Guo H, Gao C and Kuo PC: Thrombin-cleaved $\mathrm{COOH}(-)$ terminal osteopontin peptide binds with cyclophilin $\mathrm{C}$ to CD147 in murine breast cancer cells. Cancer Res 67: 4088-4097, 2007

100. Chimparlee N, Chuaypen N, Khlaiphuengsin A, Pinjaroen N, Payungporn S, Poovorawan Y and Tangkijvanich P: Diagnostic and prognostic roles of serum osteopontin and osteopontin promoter polymorphisms in hepatitis B-related hepatocellular carcinoma. Asian Pac J Cancer Prev 16: 7211-7217, 2015.

101. Sharma A, Hong S, Singh R and Jang J: Single-walled carbon nanotube based transparent immunosensor for detection of a prostate cancer biomarker osteopontin. Anal Chim Acta 869: $68-73,2015$

102. Faria M, Halquist MS, Yuan M, Mylott W Jr, Jenkins RG and Karnes HT: Comparison of a stable isotope labeled (SIL) peptide and an extended SIL peptide as internal standards to track digestion variability of an unstable signature peptide during quantification of a cancer biomarker, human osteopontin, from plasma using capillary microflow LC-MS/MS. J Chromatogr B Analyt Technol Biomed Life Sci 1001: 156-168, 2015.

103. Meirinho SG, Dias LG, Peres AM and Rodrigues LR: Development of an electrochemical RNA-aptasensor to detect human osteopontin. Biosens Bioelectron 71: 332-341, 2015.

104. Chen H, Mei Q, Jia S, Koh K, Wang K and Liu X: High specific detection of osteopontin using a three-dimensional copolymer layer support based on electrochemical impedance spectroscopy. Analyst (Lond) 139: 4476-4481, 2014.

This work is licensed under a Creative Commons Attribution 4.0 International (CC BY 4.0) License. 